\title{
A Discussion on Heuristic Teaching Mode of Professional Quality in Higher Education
}

\author{
Xiaoqiu Jia ${ }^{1, a^{*}}$ and Xiaoyu Guan ${ }^{2, b}$ \\ ${ }^{1}$ School of tranffic \& transportation, Shijiazhuang Tiedao University, Shijiazhuang, China, 050043 \\ ${ }^{2}$ School of Material Science \& Engineering, Shijiazhuang Tiedao University, Shijiazhuang, Hebei, \\ 050043 \\ ajxq082@163.com, bguanxy021@163.com \\ *The corresponding author
}

Keywords: Higher education; Professional education; Heuristic teaching method; Teaching design

\begin{abstract}
In the process of professional quality education, the heuristic teaching method is better than the injected-mode teaching method. In the specialized course teaching of colleges and universities, adopting heuristic teaching mode can effectively improve the efficiency of the students' acceptance of new knowledge. This article also discusses the characteristics of heuristic teaching in the specialized course teaching and discusses the problems that teachers should pay attention to when applying this teaching method.
\end{abstract}

\section{Introduction}

As early as two thousand years ago, Socrates who is the ancient Greek philosopher and educator used "dialogue" approach to carry out educational activities, which is early embryonic mode of heuristic teaching. He took to people in the form of discussion, but he did not directly teach the results to others, pointed out the problem and guided person to the correct conclusion [1-3].

Heuristic teaching thought after thousands of years still has a strong vitality because it is consistent with teaching rule and reflects the dialectics in teaching and learning process. The application of heuristic teaching mode can further awaken students' potential. These theoretical base have an important Inspiration for practice and application.

\section{Heuristic Teaching Mode of Specialized Teaching in Colleges}

Heuristic teaching mode should be applied in professional practice teaching in colleges and universities, which requires teachers to learn educational content and theory of teaching methodology and many related literature and try to apply to teaching practice. Aiming to students who have different knowledge background, fully mobilize the enthusiasm and cultivate their interest in learning and change "passive indoctrination" to "initiative learning", change "want me to learn" to "I want to learn." [4,5]

In using heuristic teaching in professional teaching of college, there are many issues to pay attention, such as lesson preparation and clever organization of classroom teaching. Although so-called "no fixed teaching law" wildly exists, the core issue is that the guiding teaching ideology should be correct, i.e. establishing the dominant position of students in the teaching process and rationally using heuristic teaching methods. Through the theoretic study and practical exploration, some distinctive style of professional teaching can be formed and some good teaching effect can be attained. For instance, in the classroom teaching, on the one hand, expand student's thinking to enhance the practical ability to solve problems, on the other hand, stimulate students' interest in professional knowledge. By using those teaching method, not only effectiveness of students learning new knowledge will be improve, but also their confidence is also enhance. In professional practice teaching of college education, scientific teaching methods should be a process that simultaneously mobilizes both teachers enthusiasm and students enthusiasm to realize their effective communication [6-8]. 
Teaching practice also proves that effect of teachers simply instilling students, such as speaking, student listening, taking notes and examination, is very poor, while teaching methods of two-way communication under teacher's directing can achieve better effect. However, specific practices vary in teaching. Some teachers divide their teaching content into several small sub-problems; each student who prepares the content of those titles in the class speaks in the classroom and reply the questions raised by others. After the students speaking, teachers make comments and supplement imperfectness in their content [9-11]. This more active teaching activity is very popular with students.

1. First, mobilize the enthusiasm of students self-study. In order to perfectly speak, students check information, write speeches, and careful preparation are carried out.

2. Second, discussing with each other in class can left a deep impression about problem.

3. Third, the ability to speak can be exercised. The students who never speak have also opportunities for performance.

In order to effectively guide the students to enter the learning situation, higher requirements are put forward:

4. First, teachers must have a more profoundly understanding grasping about teaching syllabus, content and the essence of spirit so that they can achieve mastery through a comprehensive study of the subject and handle very skillfully those teaching content.

5. Second, teachers must have a deep understanding of the problems existing in the students' thinking and understanding so that they can bridge the theory to practice and teach students with a purpose.

6. Third, the teacher must try their best to organization and guidance, and to guide students to achieve the content of teaching objectives.

There are two teaching modes of heuristic teaching.

Heuristic teaching methods can only be embodied in the teaching process, and the teaching process is the process of two aspects of teaching and students' learning. In the teaching process, teaching methods should be adapted to the teaching content and the actual situation of teaching objects, therefore, it is flexible used, not fixed.

Heuristic teaching is reflected in the two teaching modes:

One is the heuristic teaching mode, which is based on the teacher's classroom teaching and the students' discussion on the basic of self-study, which the teaching mode is suitable for the systematically teaching.

In order to enable students to systematically understand and master the teaching content for a new lesson, teachers should systematically teach in class. The systematically teaching in class should strive to implement the principle of combining theory with practice, highlight the key, targeted teaching. And discussions in class under the guide of teachers will be helpful for students to understand and master the new knowledge and to eliminate their ideological confusion.

The other heuristic teaching mode is primary self-study and the minor teacher's guidance, and this teaching mode is suitable for thematic teaching.

These two kinds of teaching modes have their own advantages and disadvantages. Students' learning activities include various forms. Specifically, the college professional practical and heuristic teaching has the following three basic characteristics.

Subjectivity. That is, teachers should regard the students as host in the teaching process; try their best to change students' subordinate and passive status into positive and proactive status.

Injected-mode teaching does not pay attention to host status of the teaching object and to their participation, such as simply teachers saying and students listening, which strangle the students' intelligence and personality skills.

On the contrary, heuristic teaching is that the teaching is in order to student's learning. Teaching purpose is to make students really understand and grasp knowledge. Students are host of learning. The main teachers' duty is to play a leading role in teaching. Teachers, as much as possible, inspire and guide students to actively participate in teaching activities, try to awaken and cultivate the students' host consciousness, and create students independent personality. 
Therefore, student learning must be completely voluntary and must have the enthusiasm and initiativeness.

Initiative. Actively guiding and activating thinking make students be in a positive consciousness state. Heuristic teaching believes that teaching and learning is a contradictory unity and if there is no dynamical response from the students, it is not "heuristic" at all.

Students' host can have a variety of forms of expression and its core idea is the state of thinking activities. To this purpose, heuristic teaching requires that teachers should follow the "teaching for learning" services principle to select teaching content, to use a variety of teaching methods, to create problem scenarios, to stimulate student interest in learning and to make students' be in the best state of mind. Teaching in class should be carried out on the basic of research and discussion, should be not rigidly scripted, the time left by teacher is enough for students to think and the opportunity to express their views should be given. Thus, the students' positive thinking and study can be produced. Simultaneously, teaching should be closely linked with reality. Using lifelike image, the real touching scene and intriguing philosophy to deeply attract and impress students, so that classroom teaching becomes an interesting activities.

Creativity. That the purpose of heuristic teaching is to focus on the development of students' intelligence and to encourage students to explore independently from knowing of it to grasp it. Heuristic teaching that the main teaching purpose is not simply to impart knowledge, but through the imparting of knowledge to improve students' intelligence, to promote students to explore independently, to change from learning into learn, from learning to creation. If this purpose is abandoned, heuristic teaching does not also exist.

The three characteristics of heuristic teaching tells us that first of all, students should be regarded as a host in the complex process of teaching and learning, thus teachers should do everything to mobilize the initiative of students learning; the core of heuristic teaching is to use various means to activate thinking, so that students are always in a positive state of mind; the main purpose of heuristic teaching is to develop students' intelligence and improve their creative ability.

Grasping these three points can also grasp the spiritual essence of heuristic teaching.

1. Teaching is the induction, teachers must inspire students' initiative to learn, to guide students to automatically go ahead with their own walk rather than be holden by teachers.

2. Teachers must inspire students to learn the self-consciousness, inspire their confidence, and encourage them to improve themselves, rather than suppress the students' initiative, so that they passively accept.

3. Teachers must inspire students to learn the enthusiasm, encourage them to think independently, rather than replace the students to make conclusions.

\section{Summary}

Professional education in professional quality of higher education is a complex systematic project, which requires the dual role of teaching and learning. Therefore, it is necessary to explore the scientific teaching method suitable for this process. This article discusses the characteristics of heuristic teaching methods in professional quality of higher education and some problems that teachers should pay attention to when using this method. These discussions provide useful reference for teachers how to improve the teaching of specialized courses.

\section{Acknowledgment}

The research about this title is sponsored by:

Reformation Project of Shijiazhuang Tiedao University Teaching Mode: Cultivating students' Comprehensive Professional Quality of Traffic \& Transportation Profession by "Practical Teaching" and "Heuristic Teaching" Mode;

Hebei Province Department of Education: The Research and Practice on Teaching Reformation of Higher Education in Hebei Province (2015GJJG094); 
Education and Science Project in Twelfth Five of Shijiazhuang Tiedao University (Y201416).

\section{References}

[1] Bruce Joyce, Marsha Well and Emily Calhun: Models of Teaching (PHI Learning Private Limited, 2009).

[2] Jeannie Oakes and Martin Lipton: Teaching to Change the World (2nd ed., Routledge, English, 2002.

[3] Hong Zhao: Research-oriented teaching and the reform of teaching methods in universities, Higher Education Research (In Chinese), Vol. 27 (2006) No.2, p71.

[4] Tao Zhu, Heng Ma and Qiang Liu: Research on Teaching Methods in the Case of Professional Technical Courses, Journal of Higher Education Research (In Chinese), Vol. 33 (2010) No.1, p91.

[5] Mei Xiong: Research on Heuristic Teaching Principles (Higher Education Press (In Chinese), Beijing, 1998).

[6] Li Yang and Yuexian Tao: The Evolvement and Development of Heuristic Teaching Mode, Journal of Sichuan Institution of Education (In Chinese), Vol. 20 (2004) No.1, p1.

[7] Yu Wu: Re-understanding of Heuristic Teaching, Chinese University Teaching (In Chinese), Vol. 10 (2011) No.1, p1.

[8] Siyi Shen and Shicai Qin: Contemporary Teaching Method (China Materials Publishing House (In Chinese), Beijing, 1989).

[9] Xiaohui Chen: Instructional Dessign (Electronic Industry Press (In Chinese), Beijing, 2009).

[10] Shuxin Zhang and Guancheng Liang: Cognitive Science, Constructivism and Mathematics Teaching (Shanghai Education Press (In Chinese), Shanghai, 1998).

[11] Hongiia Ma: Discuss on Teaching Strategy of Scientific Education with Scientific Inquiry as the Core (Higher Education Press (In Chinese), Beijing, 2008). 